\title{
Musicality as an Aesthetic Process of Filtering in Thomas W. Shapcott's Poetry
}

\author{
Muslim Abbas Eidan Al-Ta'an* \\ Faculty of Languages and Translation, University of Kufa, Najaf, Iraq
}

Corresponding Author: Muslim Abbas Eidan Al-Ta'an, E-mail: dr.muslimeidan@yahoo.com

\section{ARTICLE INFO}

Article history

Received: June 14, 2017

Accepted: September 04, 2017

Published: October 31, 2017

Volume: 8 Issue: 5

Advance access: October 2017

Conflicts of interest: None

Funding: None

\section{Key words:}

Shapcott,

Musicality,

Aesthetic Balance,

Aesthetic Conformity,

Aesthetic Process of Filtering,

Musical Rituality

\begin{abstract}
How does music transcend individual experience? Is music the filter to purify everything? How does everything in the poet become music? Such questions are raised, now and then, by the conscious reader of poetry in general and that of the Australian poet Thomas W. Shapcott in particular. My present research-paper attempts to present an answer for these questions via probing the individuality of Shapcott's poetic experience and how does the poet's personal and experimental musicality as an artistic motif and aesthetic perspective play a key role in purifying language of its lies and its daily impurities. In the first place, my account is apt to find an aesthetic meaning for the action of transcending the individual experience in selected poems written by Shapcott. The philosophical and ritual thought of musicality is interplayed with the aesthetic power of poetry. Both aesthetic energies stem from the individual experience of the poet to transcend the borders of individuality and being absorbed and saturated in the wide pot of human universality. In other words, the poem after being filtered and purified musically and aesthetically is no longer an individual experience owned by its producer only, rather it becomes a human experience for its conscious readers. Music as a motif and meaning, regardless of its technical significance, is controversial in Shapcott's poetic diction. Music, here, is not a mere artistic genre; rather it is a ritualistic and philosophical thought. The paper is to investigate how Shapcott's musicality is constructed on aesthetics of balance and conformity in poetry and life.
\end{abstract}

\section{INTRODUCTION}

...Music transcends

Individual experience.

Music is the filter to purify

Everything. Everything in me

Became music (Shapcott, 2006, p.61).

The above lines were quoted from a Shapcott's poem entitled, 5.1955 Eugene Gossens Knighted for his Services to Music. It is worthwhile to make an aesthetic debate over the key elements of this poetic extract in terms of probing musically and aesthetically the inward and outward details of the pigeon-hole of Shapcott's poem. Everything needs to be filtered aesthetically taking into account the matter of balance between the inward music of things and the aesthetic cadence of the outward reaction. Jorie Graham asserts that "each poem is in the end an act of mind that tries, via precision of seeing, feeling, and thinking to clean the language of its current lies, to make it capable of connecting us to the world" (qtd. in interview with Judith Beveridge by Robbie Coburn, 2015). In Music at Hand (2017) Jonathan De Souze acknowledges that:

Music is fleeting. It disperses as it is heard. And though I sometimes

feel its vibrations, I cannot touch, cannot see, and cannot hold them.
Because of this, music has often been considered the most abstract,

most metaphysical art. Yet at the same time, music is bound up with

physical things: upright pianos and electric guitars... horns, marimbas,

headphones, flutes of metal, bone, or wood. And all of these, in turn,

are bound to human bodies $(2017$, p.1).

After being aesthetically filtered music is no longer an auditory phenomenon only; rather it can express all human senses associated with the aesthetic action as man's energy is still active and appealing. Richard Hugo thinks that once a poet starts writing poetry he is apt to "carry to the page one of two attitudes... One is that all music must conform to truth. The other, that all truth must conform to music" (1979, p.2). To my mind, the point could be read within the aesthetic frame of reciprocal dialogism between music and truth. To carry any sensual experience to the page demands much more effort on the part of the poet. The presence of the poet is not a mere physical one, it should be purely musical. The pure musicality doesn't come true unless there is an aesthetic process of filtering the raw poetic language of all its impurities. Shapcott, as an experimental poet, focuses on such conformity between two musical and sensual experiences: 
the first comes out that harmony between the fingers and the pen; the second is that of an aesthetic accordance between a remote deep-rooted sound that air delicately carries and the poet's ear. Devin Johnston argues that "[p]oetry is a matter of presence, whether on the page or in the air..." (Poetry, 2016, p.112). I think that the fertile and purified musicality of the poet both-in terms of being a storehouse of aesthetic thoughts, and a transparent vehicle of the text which aesthetically 'transcends the individual experience' of the poet and makes it belong to his reader. Here does the aesthetic musicality lie. T. S. Inglis Moore sees that Shapcott "is fecund, confining himself to a fluted delicacy", and he "has a wider orchestral range" (Moore,1967, p. 13). Drawing on that, I think that 'fluted delicacy' or delicate flutedness might indicate the poet's lyricality, regardless the decade, he physically lives in. After transcending the personal by means of the musical, the poet consciously or unconsciously, feels purified. Metaphorically his new feeling might make him soar 'in the air' and his spiritual musicality might instill its poetic rituality 'on the page'. Every word has its own musicality whether in tone or in the connotative roots from which its energy stems. Tenderness of the fluted moment is the very start of the state of musical purification. Construction of the lyrical diction is a micro realm for poetic, especially lyrical, language which is apt to be metaphorically expanded in terms of sensual tone or lexical music. The lexical sense of 'flute', for instance, is that of a "high-pitched woodwind instrument held sideways" (Waite, et al., 1998, p.245). The action of being fluted in poetry, to me, is a lyrical effort done by the poet in order to purify language both lexically and aesthetically by means of filtering it via playing on the moment's flute in order to make groovy hollows or aesthetic channels in the body of the very language. In other words, digging so deep in the aesthetic soil of the experience is a matter of musical purification. Therefore, playing on the text's flute by poetic fingers is not only a story of sensuality, rather it is a process of transcending the personal experience for the intention of being purified both musically and aesthetically. This action never comes true without the boundless energy of the poet's aesthetic digging.

Shapcott the lyrical poet, in his formative poetic years, sounds groovy as he simply transforms the normal daily experience into a new purified, ritual, musical and poetic experience. For Shapcott I claim that the daily conversation with the self or the other takes a form of musical rituality. Such kind of aesthetic conversation will produce a new musicality of poetic language. Camille Martin argues that, "[i[t's not only ritualistic or condensed poetic language that exhibits musical rhythm; ordinary conversation can be extraordinarily musical" (2010). Having 'a wider orchestral range' means that the poet makes an aesthetic conformity between what he plans to orchestrate on page and what dreams to sing poetically in the air, i.e, to arrange and prepare its potential energy or energetic potentiality to a moment of musical purification; to arrange its musical elements for an aesthetic desired effect of dreamy melody. The poet's fingers are aesthetic keys to unlock the locked terrains of a virgin language in a mysterious terra incognita. The poet, I think, is able enough to create his own poetic myth after filtering musically the details of the sensuous narrative moment of the daily book of experiences he passes by. After transcending the borders of personal experience, the poet's music becomes mythological since it establishes a new purified tradition for aesthetic musicality. The aesthetic map of both- the lyrical and the orchestral thematic setting may lead us to read about Shapcott's personal background in music from the early formative years of his poetic career. Here are some important quotes and comments manifesting Shapcott's love of music related to the poet's family background since his childhood in Ipswich:

-'From that background, in my family, as I grew up, there was a strong

love of music. My grandfather had been an active member of the

Blackstone -Ipswich Cambrian Choir...he had a bass voice and was

clearly musical. My father wasn't very musical, he had a nondescript

singing voice, he had a pleasant speaking voice which I'm told I inherited

and probably some of the accent he got from his father, but he didn't

have much of a singing voice. He played the piano a little bit. I actually

was very musical and this came out when I was a little kid...Mrs. Burns

or Mr. Burns ['the people next door'] cornered my father once and said

"Tom should have lessons because he is always playing the piano and

actually making nice sounds", or words to that effect... and I was the

only one who kept on with it [music] up to ATCL level" (Buchanan, 1995, pp.1-2).

-In addition to being "[a] lavish writer of poems, novels and short stories

Shapcott has also collaborated with several composers, notably Colin

Brumby" (Jordan, 2004, p.270).

-It's worthwhile to mention here: Shapcott: The seven deadly sins, poems for the

opera. Music for the opera by Colin Brumby (1970).

-I originally wanted to be a serious composer; during Ntional Service

in 1954 I found I could keep a notebook (not a piano) in my pocket.

I had always written verse, but now I took it seriously (Interview with Shapcott, 2010,

p.29).

My aesthetic account on the key presence of music both in Shapcott's life and poetry might be understood in terms of a double-sense reading: one stems from my romantic philosophy of music as an artwork dealing with 'the language of emotions', the second one is related to the perspective of 
'aesthetic distance' by means of which I've been involved or given a room in the text to join its creator aesthetically and emotionally from my position as an aesthetic reader. Moreover, the aesthetic account of reading the textual musicality of Shapcott's poetry might be constructed on a sensual base of feeling poetry as an area of 'musical aesthetics' or as a genre of aesthetic musicality. The philosopher and musical critic Roger Scruton maintains that "the subjects of musical aesthetics [are]: sound and how we perceive it, the relation between sound and tone, the nature of melody, rhythm and harmony, the standards of taste and judgement" $(2009, \mathrm{p} .3)$. Regardless the technical significance of these 'subjects', my aesthetic account is dependent on understanding the aesthetic energy of the poetic, narrative and dramatic moments in Shapcott's poetic experience. In other words, I should be-as an aesthetic reader- aware of understanding the analogical relation between language and music in Shapcott's poetry. Such a musical awareness of the aesthetic and narrative moment of the experimental poem makes us think of the potentiality of details or innerness of things in the course of our lives, in terms of how do we keep "using them with an [aesthetic] eye to their sensuous qualities", according to Eagleton (2007, p.41).

In an interview on prose poetry, it comes true that Shapcott in his Turning Full Circle does "use the image of music from time to time" in order to "have that sense of development of motif, its recurrence and variation" (Shapcott,1982). Thomas Shapcott debates over such musical concerns in poetry saying:

In my collection there were certain recurring motifs and a self-conscious

preoccupation with 'turning full circle', of ending up where you started-

but you never come back to where you started with exactly the same

perspective... One has preoccupations in any time of one's life. But others

which are much more basic come through. For the very last group I looked

back-and then I tried to do different things, partly because I felt I had been

following a certain thread, seeing where it led, and suddenly I thought: no

there other things that can be done too in this form (Shapcott, 1982).

As an aesthetic reader of Shapcott's poetry, whether its cadence rhythmical or prose one, my account is grounded on its aesthetic tapestry focusing on its power of spelling the reader to be involved consciously or unconsciously in the aesthetic details of the text. I think that the aesthetic 'thread' that might Shapcott invite his reader to follow is that of a musical game of "turning full circle" one's senses. John Hollander, for instance, acknowledges that "[i]n the world of the ear, poetry is a kind of music, as it is a mode of picturing in the context of the eye" (1975, p.3). To Shapcott, musicality in language of poetry, whether it is sensual, high-pitched or tonal, is also a kind of an aesthetically experimental effort leading to a pure musicality of thinking. The aesthetic reader of his text might feel the sense of interconnectedness of the aforementioned moments strongly associated with each other by a 'thread' of pure musicality. Bye and large, the pure aesthetic musicality of Shapcott's poem may work as a web of fascinating senses as if they were exchanging aesthetic messages for "eye and ear [are] standing as thought and feeling” (1975,p.23). Such kind of sensual musicality is prevailing a wide space in Shapcott's poetry. Hollander opines that "...we all still dwell in the Romantic world of ear, in which the song of birds is more like poetry than a Beethoven string quartet" (1975, p.43). Shapcott's aesthetics has nested his poetic text to perform the game of balance in the aesthetic process of filtering between the pure romantic musicality represented by 'the song of birds' and that of that intellectually produced orchestra conducted by Beethoven and other great muscicians.

\section{ANALYSIS OF SELECTED POEMS}

Language is alimentation.

It nourishes us

Even with eyes closed.

In the beginning

Was the sound.

Sound became word.

We had to listen.

Blue is not a colour

It is a condition (Shapcott, 2006, p.8).

In his poem, Language, Shapcott likens the story of creation to the first formation of language. In other sense, he might regard musicality of sound from which the word stems as a starting point of framing the human language. Throughout such a kind of musical fecundity, an aesthetic transformation in language could occur when 'blue is not a colour/ It is a condition". There is a kind of dialectical relationship or aesthetic recriprocality between two artistic energies: pure musicality of poetry and music of colour. Camille Martin assures that "[w[e also call some poetry 'musical' in the sense of 'painterly' - words used as colours and texture painted onto a canvas, arranged in such a way to give aesthetic and intellectual pleasure" (2010). Such aesthetics of dialogicality occurs musically between 'words' and 'colours, 'canvas' and the painter's fingers. To my notion, it is the magical power of music that can make the act of filtering and purifying that could happen in the terrain of language and the surface of the painting. The 'aesthetic or intellectual pleasure' never comes true without the musical energy that purifies everything in the world.

Reading a new experimental poem-that of a musical experience-is like walking barefooted in a thorny path; it is a matter of being so sensitive and challengeable since "sensitivity is a challenge", to use the words of the poet and publisher David Musgrave (Interview by Daniel Xerri,2016, p.200). Each poem written by Shapcott is a new experience clothed with musical sensitivity or sensitive musicality that the reader needs to be aware of its fluidity, beauty and humanity. Shapcott, consciously or unconsciously, invites his reader to be sensitive and attentive to the attributes of "the fluid, tender, [and] humane attitudes expressed" in the text whether by the poet himself or his poetic protagonists 
themselves (Hugo, 1979, p.9). The experimental poetics of Shapcott could be characterized by that sort of harmony between the self-sensitivity and the physical musicality of life due to his being "concerned with exploring ways of balancing essential lyrical expression with the cadence of lyric speech", as he has mentioned in a short comment in Contemporary Poets (2001,p.1078).

Shapcott's musicality has a genetic rootedness. As a son of a migrant in a multi-cultural country like Australia, Shapcott is still in a quest for a musical conformity between the old and the young. Such a musical dialogism might occur between fancy and reality. Shapcott's imagination, by and large, is active in making aesthetically a musical dialogue between the present inner-self of the poet and the "genetic heritage...[and] this is the kind of material that the best poems of Shapcott's [The city of empty rooms] have worried about", to use the words of Martin Duwell (2007). He always sheds the light on the significance of his ancestors in such a respect. In reading a poem called, Looking for Ancestors in Limerick, Duewell acknowledges that "Shapcott makes it clear that he took not documents but his own self-actually a highly distinctive genetic document-when he went searching for his grandmother's family" (2007). Shapcott narrates his musical trip with a mythological tone:

Take a myth with you they said.

I took memories of my grandmother and forgot

Death certificates, marriage documents-there was no

Birth certificate. I took myself.

My grandmother had a voice like musical bottles

And a temper like my daughter. She swore

In the language of petulance in her old years (Shapcott, 2006, p.17).

Here, Shapcott brings back some musical memories of his grandmother who might signify a mythological generation of ancestors who had created their aesthetic musicality by means of the powerful popular imagination. The musical tone of the grandmother belongs to such a folkloric and old tradition of making their own musicality by tapping bottles of water in order to produce a variety of musical pitches. Brooke Rowe argues that "playing musical bottles explores how different pitches of sound are made. In this experiment, glass bottles are filled with water and tapped with a spoon. High and low pitches are a result of sound vibrating in the bottle, the more water in the bottle the lower the pitch" (2016, p.3). So, 'water', here, is not only a source of life, it is a source of musicality as well. I think that the musical store of the poet's family is still energetic and aesthetically providing him with a new energy of reading the musical gap between certificates of death and those of birth, old years represented by the grandmother and young ones by his daughter. In other words, it could be called a mythological-generational music as the poet, via such a family myth of the old woman's voice which is magical enough to mythologize the past and to aesthetically re- invent it into a new energetic and musical present. Shapcott himself asserts that “[w]hat I'm concerned about is re-inventing the past, renewing it, making it present" (Interview by Williams, 1998, p.208). In another poem namely, Reclaim, Shapcott, as in the previous poem, focuses on "the same setting", and "we [readers] see the poet beginning by rejecting angrily the kind of genetic determinism that leads people to assume resonances but being led, at the end to accept that no individual is utterly self-contained when it comes to physical and psychological features", as Martin Duwell debates over it (2007). In spite of the bitter musicality of being in angry mood, Shapcott invites us to discover musically 'the truth' and to read again in order to know about the aesthetic narrative moment;

....

I felt anger.

No, I felt drawn in

I was who I was and it had nothing to do

With them.

....

My life had been discovery and the truth

Though it seemed everything was sudden

And unfamiliar.

I can negotiate that Shapcott, in this poem, plays on a harp of 'exile' to present his readers a new aesthetic sense of musicality associated with both- the talent of singing and cadence of telling 'stories':

Sing us your songs,

They said, or tell us your stories.

We all feel the hard soil of exile.

Such melancholic atmosphere is musical as it deals with private feelings of the poet's voice and those of the exiled fellows who have a common sense of pain they 'all feel on the hard soil of exile'. This metaphorical setting may take us, by means of aesthetic distance, to probe the 'soil of exile' in order to feel the aesthetic musicality of human pain and suffering implicitly or explicitly. The poet, too, may continue his aesthetic journey as if he were romantically recollecting some distant musical voices of his ancestors:

I said I will sing a song

There is no story like the lonely song

of exile

We hear your genes they said.

Welcome

....

And the ancestral voices were as foreign

And familiar as each part I sought to disown (Shapcott, 2006, p.15-16).

I think that musicality is an aesthetic and thoughtful vehicle that can "convey the greatest quality of thoughts with the smallest quality of words", as it is argued by Ezra Pound (qtd. in Peter Nicholas: Poetry and Rhetoric, Modernism and Beyond, 2011, p.6). To my mind, Shapcott is the master of the aesthetic game of 'balance' between the two qualities of 'thoughts' and 'words'. He is quite skillful and confident as he holds their aesthetic threads and claims that:

Music has been weighed in the balance

Like any other object. It is as if

We might hold the scales.

This why only we can agree

They are all right.

Allowing us to decode the music as symptomatic

Or in sympathy with each very decade. 
Yet somehow things are not right.

Something's omitted. There is the squint

Of the specific man, there is the convention

Or the breaking of convention.

But how do we fit the silences

In our Balance sheet?

We are restricted

By the very idea of balance (Shapcott, 2006, p.50).

Being 'restricted/by the very idea of balance' shows that Shapcott is still strongly stick to his own musical philosophy. I think that Shapcott's aesthetic balance is present even in his musical attempt to 'fit the silences'. The poet alone reads the music of silence as he is 'the specific man' that could agree with 'the convention' and keep 'breaking' it at the same time. The poet's eyes have a musical 'squint' that might glance in different directions with a confident aesthetic balance. The poetic balance creates the cadence of musicality; it sharpens the energy of holding 'the scales' for the sake of filtering 'any other object' musically and aesthetically. Furthermore, in the third section which is specialized to artistic and musical concerns in his poetic collection, The city of the empty rooms, Shapcott tackles recurrently a very crucial issue concerning "the individual and his or her double status as genetically determined object and free-floating self" (Duwell, 2007, p.). By means of aesthetic balance which is a key element in the process of the musical filtering, Shapcott might abridge the gap between the individual experience as 'a determined object' and the state of 'the free-floating self' after the aesthetic transcendence comes true. In Shapcott's “intriguing poem", Mozart, Mahler, Those Russians, the critic Martin Duwell reads the aesthetic setting with analytical eye:

...this double-status is worked out as a meditation on the old literary-historical

issue of art's relationship to its times. In Mozart a function of his period or a

free-formed genius? Both and neither, the poem seems to say. Though "I hear

the tumbrels/beyond the next all'ee/in Mozart", the balanced structures of

Vienese classical music are balancing between surface and an understood and

Registered deeper reality, here symbolized by the stubble and the head rash under

the aristocracy's wigs. The temptation to read music as a response to the horrors

of its period (the emerging determinism of psychology in the Vienna of Mahler's

day, the mad Stalinist regime overlooking Prokofiev and Shostakovich) tells a lot

of the truth but not, it seems, all of it (Duwell, 2007).

In the third stanza of the poem-portrait- Genevieve, in The Period Portraits, Shapcott depicts another setting in which he casts the light on the key poetic character in whose musical background may raise significant questions about the game of senses and the role of aesthetic memory in such a musical narrativity. I think that music of thought is what attracts me more to the heart of the very poem. In the first place, it is the music of the "free-flowing thoughts" in which, as a reader, I get involved with aesthetic sensation (Eagleton, 2007, p.7). The last stanza opens a new window for readers to participate in the game of senses:

At boarding school she was praised for elocution

as well as her piano. She still plays some pieces perfunctorily.

Somehow it isn't the same. Beethoven died centuries ago and who is there to listen, anyhow? Genevieve still practices,

it is the only way, and she sees it as a sort of victory over the past? Over time? Over all the others ever were? Somehow the music has become, at most, a sort of cage and it is years since anyone, including herself, has really listened.

That lovely speaking voice, too, has grown dulled from lack of practice.

These were not the things her husband prized in her.

He saw her, once, riding across his to paddock

and he knew immediately that she was the only one.

So it goes. She does not speak of disappointment,

nor does he. They both recognize the fact: she was the only (Shapcott, Period Portraits, 2009, p.10).

Here, I feel that there is a sort of aesthetic musicality related to a sensitive narrativity. Both, the poet and his reader, may uncover some hidden narrative moment in the personal history of the poetic protagonist Mrs. Genevieve. Both the personal feeling and the musical language are being in a process of aesthetic contact. In other sense, they are aesthetically tied up with a narrative moment. The talented lady who was superior than anybody else in the art of clear and expressive speaking and playing 'the piano', never utters a word of any 'disappointment', nor does her husband due to the aesthetic balance of musicality in their life as '[ $\mathrm{t}]$ hey both recognize the fact' musically. The lady, by playing on piano, makes a victory over all past passive attitudes and disappointments. Musicality is related to the psychological moment of man. Music is used as a code of freedom, if it is keeping its key role in purifying and faltering process, however, it can be decoded not as an aesthetic 'symptomatic' but as a 'sort of cage'. I think that this aesthetic expression is a kind of expanded metaphor. Such thing occurs when the musical balance is lost. The tale of the protagonist of the poem may tell us about unstable times in course of her life. Aging time may cause problematic situations as the 'lovely speaking voice, too, has grown dulled from lack of practice'. However, the musical spark is still there. The fingers of the lady may ignite it in order to make poetics of the narrativity musical, and musicality of language, after being aesthetically filtered, a purified aesthetic reality.

\section{CONCLUSION}

It comes true to conclude that poetry, whether it is an art of verbal creation or within a new experimental frame, is still a sensual action of an aesthetic and musical experience. By the eye of imagination and the hand of sense, by the romantic ear and the real tongue, one can see, touch, hear, taste 
and utter the poetic music. The raised questions at the very start of introduction: how does music transcend individual experience?, is music the filter to purify everything?, and how does everything in the poet become music? could be answered via probing the individuality of Shapcott's poetic experience and how does the poet's personal and experimental musicality as an artistic motif and aesthetic perspective play a key role in purifying language of its lies and its daily impurities. In the first place, my account comes true in terms of finding an aesthetic meaning for the action of transcending the individual experience in selected poems written by Shapcott. The philosophical and ritual thought of musicality is interplayed with the aesthetic power of poetry. Both aesthetic energies stem from the individual experience of the poet to transcend the borders of individuality and being absorbed and saturated in the wide pot of human universality. In other words, the poem after being filtered and purified musically and aesthetically is no longer an individual experience owned by its producer only, rather it becomes a human experience for its conscious readers. Music as a motif and meaning, regardless of its technical significance, is controversial in Shapcott's poetic diction. Music, here, is not a mere artistic genre; rather it is a ritualistic and philosophical thought. The paper is apt to investigate how Shapcott's musicality is constructed on aesthetics of balance and conformity in poetry and life. In Shapcott's poetic text, music has a new aesthetic account that the poet may manifest his philosophical musicality when he uses it as a tool of transcending the personal in order to put on an aesthetic universal dress. When music takes the function of an aesthetic filter for the end of purifying everything, he constructs his musical dome by means of which one can purify himself/herself of the polluted thoughts and the daily lies of language. After being aesthetically filtered music is no longer an auditory phenomenon only; rather it can express all human senses associated with the aesthetic action as man's energy is still active and appealing. To my mind, the point could be read within the aesthetic frame of reciprocal dialogism between music and truth. Thus the point of carrying any sensual experience to the page demands much more effort on the part of the poet. The presence of the poet is not a mere physical one, it should be purely musical. The pure musicality doesn't come true unless there is an aesthetic process of filtering the raw poetic language of all its impurities. Shapcott, as an experimental poet, focuses on such conformity between two musical and sensual experiences: the first comes out that harmony between the fingers and the pen; the second is that of an aesthetic accordance between a remote deep-rooted sound that is carried delicately by air and the poet's ear. I think that the fertile and purified musicality of the poet both-in terms of being a storehouse of aesthetic thoughts, and a transparent vehicle of the text- will aesthetically transcend the individual experience of the poet and makes it belong to his reader. Here does the aesthetic musicality lie. Shapcott's poetic music is not an abstract artwork. It's an aesthetic and moral thought that might teach us (the readers) who follow its philosophical cadence- a lesson about how to purify ourselves musically in order to transcend the borders of our narrow individuality; how to reach, as human beings, the top of peacefulness and alikeness in everything. Shapcott's poetry may urge our senses to be aware of the musicality of the world around us. He aesthetically invites us to understand the meaning of his aesthetic account: music is necessary as water and air in life. Its language is an aesthetic nutrition that our senses need to feed on. To make such an aesthetic balance and conformity by music, life can be read as an account of beauty, love and peace.

\section{REFERENCES}

Buchanan, R. (1995). Thomas Shapcott: Memories of growing up in Ipswich: Oral history interview. Retrieved from http://www.ipswich.qld.gov.au/data/assests/pdf file/0012/10452/01 thomas-hapcott-oral-history-smallfile-pdf.

Coburn, R. (2015). Interview with Judith Beveridge. Writ. Poetry Review, Issue 3. Retrieved from http://www.writreview.com.au.

De Souze, J. (2017). Music at hand, instruments, bodies and cognition, Oxford studies in music theory, New York: Oxford University Press.

Duwell, M. (2007). Tom Shapcott: The city of empty rooms, Review. Retrieved from https: www.austlit.edu.au/austli/page/c778448.

Eagleton, T. (2007). How to Read a Poem. Malden and Oxford and Victoria: Blackwell Publishing.

Edmonds, P. (2010). Interview with Thomas Shapcott, Wet Ink, (18)28-31, Australia, Wet Ink Magazine Inc.

Holander, J. (1975). Vision and resonance: Two senses of poetic form, New York: Oxford. University Press.

Hugo, R. (1979). The triggering town. New York\& London: W. W. Norton\& Company.

Johnston, D. (2016). A note on the editor. In Poetry: Australian poets. (208),2. Poetry Foundation.

Jordan, D. (2004). Thomas W. Shapcott. In Selina Samuels (Ed.), Australian writers, 1950-1975: Dictionary of literary biography. Gale.

Martin, C. (2010). Musicality in poetry. Retrieved from https://rogueembryo.com/2010/03/15/musicality-in-poetry/.

Moore, T. S. I. (1967). Disciplined clarity in poet's new work. In The Canberra times, November 11, p.13. Retrieved from http://trove.nla.gov.au/newspaper/article/106981889/.

Nicholas, P. (2011), Poetry and rhetoric, modernism and beyond, USA: New York University.

Riggs, T. (Ed.). (2001), Contemporary poets. USA: St. James Press.

Row, B. (2016), Playing musical bottles. USA: Cherry Lake Publishing.

Scruton, R. (2009). Understanding music: Philosophy and interpretation. London \& New York: Continuum.

Shapcott, T. (1982). Interview with Mattoid on prose poem. Text: The journal of the Australian.

association of writing programs.(2002), (6), 2. Retrieved 
from http://www.textjournal.com. Au./oct2/letters/htm Shapcott, T. (2006). The city of empty rooms. UK, Cambridge: Salt.

Shapcott, T. (2009). "Period portraits", Wet ink, Issue (15)10-15, Australia, Wet Ink Magazine Inc.

Waite, M., Hodgson, A., Howes, A., Jones, L., Paton, B., and St John- Hall, A. (1998). Little Oxford dictionary. New York: Oxford University Press.

Williams, B. (1998), In other words, interview with Thomas W. Shapcott, Amsterdam, Rodobi.

Xerri, D. (2016), Interview with David Musgrave in Symposia Melitensia, Number 12 